\title{
REVIEWS
}

\section{Fine-control of Metal Assembling in Dendritic Polyphenylazomethines}

\author{
Kimihisa YAмамото ${ }^{\dagger}$ and Masayoshi HiguCHI \\ Department of Chemistry, Faculty of Science and Technology, Keio University, Yokohama 223-8522, Japan
}

(Received April 19, 2004; Accepted April 19, 2004; Published August 15, 2004)

\begin{abstract}
Dendritic polyphenylazomethines (DPAs) with a regularly branched structure and a single molecular weight were synthesized using the convergent method. DPA derivatives having tris(thienylphenyl)amine and tetraphenylporphyrin as the core (TPA-DPAs and Por-DPAs) and aniline-capped DPAs were obtained during the dehydration of the DPA dendrons with tris(4-aminothienylphenyl)amine, tetra(4-aminophenyl)porphyrin, and aniline, respectively. We exploited the more efficient synthetic method of DPAs, and successfully obtained the fifth generation of DPA (DPA G5). Stepwise radial complexation with $\mathrm{SnCl}_{2}$ in DPAs, TPA-DPAs, Por-DPAs, and aniline-capped DPAs, was found as stepwise shifts of the isosbestic point during the UV-vis spectroscopic observation. This complexation behavior was supported by the shell-selective reduction of the imines. Using the shell-selective reduction method and the terminalmodification method of the DPAs, the core and terminals of DPAs were functionalized by a ferrocene unit(s), respectively. $\mathrm{FeCl}_{3}$ molecules were also complexed with the imines of the DPAs in a stepwise fashion. Encapsulation/releasing of Fe ions in DPA was electrochemically controlled due to the different complexation ability of $\mathrm{Fe}$ (II) and $\mathrm{Fe}$ (III) ions with the imines. TPA-DPAs were applied as hole-transporting materials in EL devices. Their efficiency was found to be enhanced when complexing with $\mathrm{SnCl}_{2}$. [DOI 10.1295/polymj.36.577]

KEY WORDS Dendrimer / Phenylazomethine / Stepwise Complexation / Electron Gradients / Nano-materials / Drug Delivery / Electro-luminescence Devices /
\end{abstract}

Biological reactions such as photosynthesis ${ }^{1-4}$ in plants or respiration ${ }^{5,6}$ in animals are based on highly efficient electron or ion transfer of which the direction, amount, and rate are controlled in the metal-containing proteins. Such efficient transfers are caused by the definite configuration of metal ions in the proteins. Macromolecules containing metal species such as polymer-metal complexes can be regarded as a mimic of the metal-containing proteins, and actually, a number of nature-mimetic materials based on various combinations of polymers with metal species have been reported up to now. ${ }^{7-9}$ However, most of these hybrid materials consist of only simple mixtures of organic polymers with metal species, because there are no methods for the control of the number and location of metal species in polymer materials. In addition, the recent development of nano-science and nano-technology needs novel nano-materials with clear structures in order to amplify their functions. In other words, the creation of novel macromolecules with fine-controlled metal-assembling properties are very important in the significant fields of electronics and life-science as materials of artificial enzymes, eco-catalysts, fuel cells, and drugs. We herein demonstrate the fine-control of the number and position of metal ions in polymer materials based on the gradients in electronic density generated inside the polymers.

In general, polymers have a linear structure and a distribution in their molecular weight. On the other hand, Tomalia et al. first reported "dendrimers" as regular-branched macromolecules in $1984 .{ }^{10-12}$ Since then, their unique tree-like topological structures have fascinated many scientists. ${ }^{13-19}$ The synthetic methods of the dendrimers are roughly divided into a divergent synthesis, in which the dendrimers are constructed from the core unit toward the terminals in a stepwise fashion, a convergent one, in which the dendrimers are synthesized from the terminal units toward the core. Especially, the convergent synthesis is superior to the divergent one with respect to producing homogeneous dendrimers having a single molecular weight and a single structure. The number of branchings from the core in dendrimers is called "generations" or "shells". High generations of dendrimers have crowded terminals and a spacious core, and the entire shape of the dendrimers is close to a sphere. The nano-space inside the dendrimers causes various unique functions such as light-harvesting, selective molecular conversion, and drug delivery. ${ }^{20-26}$ On the other hand, modification of the many terminals of the dendrimers can easily change their properties such as solubility. These properties of dendrimers will become useful in many fields such as medicine, electronics, energy, and micro-machines.

Dendrimers having many coordination sites are also interesting as the polymer part of the polymer-metal

${ }^{\dagger}$ To whom correspondence should be addressed (E-mail: yamamoto@chem.keio.ac.jp). 


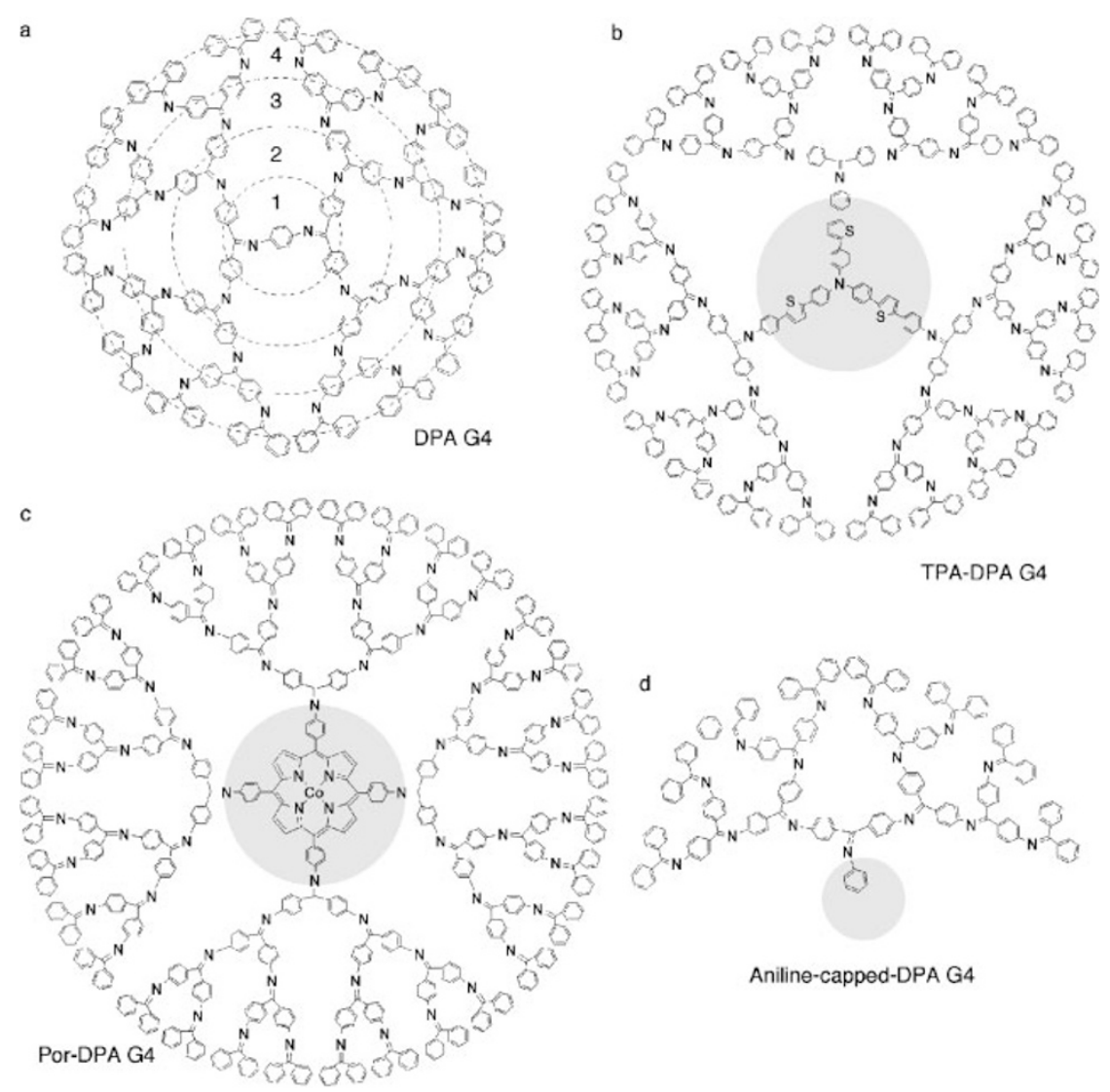

Figure 1. Dendritic polyphenylazomethine (DPA) derivatives having various cores.

hybrid materials. Many hybrid materials consisting of dendrimers with metal salts or metal clusters have been reported and applied as catalysts or electrochemical sensors. ${ }^{27-30}$ However, precise control of metal species inside dendrimers has not yet been realized until now in spite of high homogeneity of the dendrimers.

\section{SYNTHESIS OF DENDRITIC POLYPHENYL- AZOMETHINE (DPA)}

\section{The Convergent Synthesis}

As novel dendrimers having a $\pi$-conjugated backbone and many coordination sites, we synthesized dendritic polyphenylazomethines (DPAs) by the convergent method via dehydration of aromatic amines with aromatic ketones in the presence of $\mathrm{TiCl}_{4} \cdot{ }^{31-33}$ The fourth generation DPA (DPA G4) has 2, 4, 8, and 16 imines in the order of the 1st, 2nd, 3rd, and 4th shells, respectively (total 30 imines). In the convergent synthesis, it is relatively easy to induce a functional group to the core of the dendrimers. We synthesized DPA derivatives with phenyl (DPA G1-4), trithienylphenylamine (TPA-DPA G1-4), ${ }^{34}$ or tetraphenylporphyrin (Por-DPA G1-4) ${ }^{35}$ as the core. TPA-DPAs are synthesized during the dehydration of amino-terminated tris(thienylphenyl)amine with DPA dendrons in the presence of titanium(IV) tetrachloride and DABCO. Simi- larly, a series of dendrimers with a porphyrin core (Por-DPAs) were synthesized by dehydration using $\mathrm{TiCl}_{4}$ from meso-tetrakis(4-aminophenyl)porphyrin and the corresponding DPA dendron. The porphyrin core was metalled with $\mathrm{CoCl}_{2}$ in dehydrated THF. Aniline-capped DPA G1-4 was also obtained via dehydration of aniline with the DPA dendrons. TPA-DPA G4, Por-DPA G4, and the aniline-capped DPA G4 have 3, 6, 12, 24 imines, 4, 8, 16, 32 imines, and 1, 2, 4, 8 imines in the order of the 1st, 2nd, 3rd, 4th shells, respectively. The DPA derivatives were confirmed by TOF-MS, NMR, and IR.

\section{An Efficient Synthetic Method}

Recently, we succeeded in synthesizing DPA G4 over 100 times more efficiently than using the conventional one (Scheme 1). ${ }^{36}$ Byproducts are formed when using the conventional method because of undesirable dehydration of a carbonyl group from the dendron with amino groups of the monomer. On the other hand, methylenedianiline (1) is used in the novel method as a monomer instead of diaminobenzophenone. The pre-dendron G2, which does not have carbonyl groups, was obtained via dehydration of one equivalent of 1 with two equivalents of benzophenone. Side-reactions do not proceed in this reaction, because the pre-dendron $\mathrm{G} 2$ does not have any reac- 

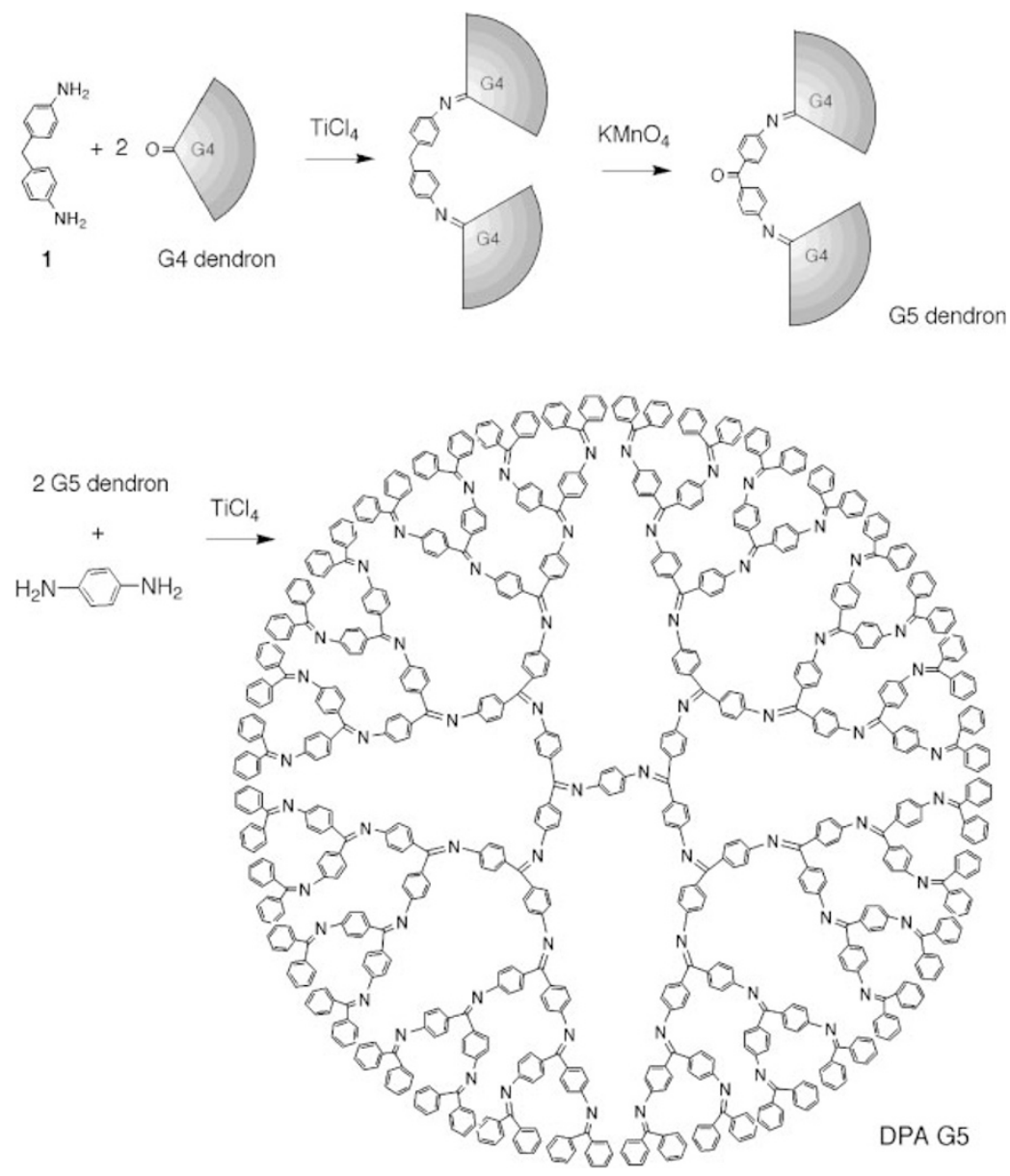

Scheme 1. Synthesis of DPA G5 using an improved method.

tive carbonyl groups. The DPA dendron G2 was synthesized by oxygenation of the pre-dendron $\mathrm{G} 2$ in the presence of $\mathrm{KMnO}_{4}$. Similarly, the pre-dendrons G3 and $\mathrm{G} 4$ were obtained by dehydration of one equivalent of 1 with two equivalents of DPA dendrons G2 and G3, respectively, and DPA dendrons G3 and G4 were synthesized by oxygenation of the obtained pre-dendrons G3 and G4, respectively. In order to prevent the formation of byproducts, an excessive amount of the ketone monomers is used in the conventional reaction. On the other hand, there is no need to use such a large amount of the ketone monomer in this novel method. In addition, isolation and purification of the products became much easier in the novel method, because of no byproducts. Though it is difficult to synthesize over fourth generation DPAs when using the conventional method, we succeeded in being the first to synthesize the fifth generation DPA (DPA G5) using this synthetic method.

\section{FINE-CONTROLLED METAL-ASSEMBLING IN DPA}

\section{Stepwise Radial Complexation}

Many metal ions can be assembled inside the DPA molecule by the strong coordination ability of the imines in DPAs. The 30 equivalents of $\mathrm{SnCl}_{2}$ should be included in the fourth generation DPA (DPA G4), which has 30 imine sites, because $\mathrm{SnCl}_{2}$ is complexed with an imine at the ratio of 1:1. Complexation of DPA G4 with $\mathrm{SnCl}_{2}$ was confirmed as a shift in the absorption based on $\pi-\pi^{*}$ transition of imines in the UV-vis spectra. During the complexation of DPA G4 with $\mathrm{SnCl}_{2}$, four shifts in the isosbestic point were observed in the spectra. ${ }^{37-40}$ If $\mathrm{SnCl}_{2}$ molecules are complexed with the imines in DPAs at random, the isosbestic point is not shifted during the titration of $\mathrm{SnCl}_{2}$. However, the isosbestic point was observed at 375,364 , 360 , and $355 \mathrm{~nm}$ during the addition of $0-2,3-6,7-$ 14 , and 15-30 equivalents of $\mathrm{SnCl}_{2}$ to the dichloromethane/acetonitrile solution of DPA G4, respectively. These shifts show that the complexation proceeds in four steps. The amounts of the added $\mathrm{SnCl}_{2}$ in each step, i.e., 2, 4, 8, and 16 equivalents, agree with the number of imines in the 1st to 4th shells. This result shows that $\mathrm{SnCl}_{2}$ molecules are assembled from the core to the terminals of DPA G4 in a stepwise fashion. A similar complexation behavior was observed in the DPA derivatives (Scheme 2). When adding $\mathrm{SnCl}_{2}$ in the solution of these dendrimers, four shifts were ob- 

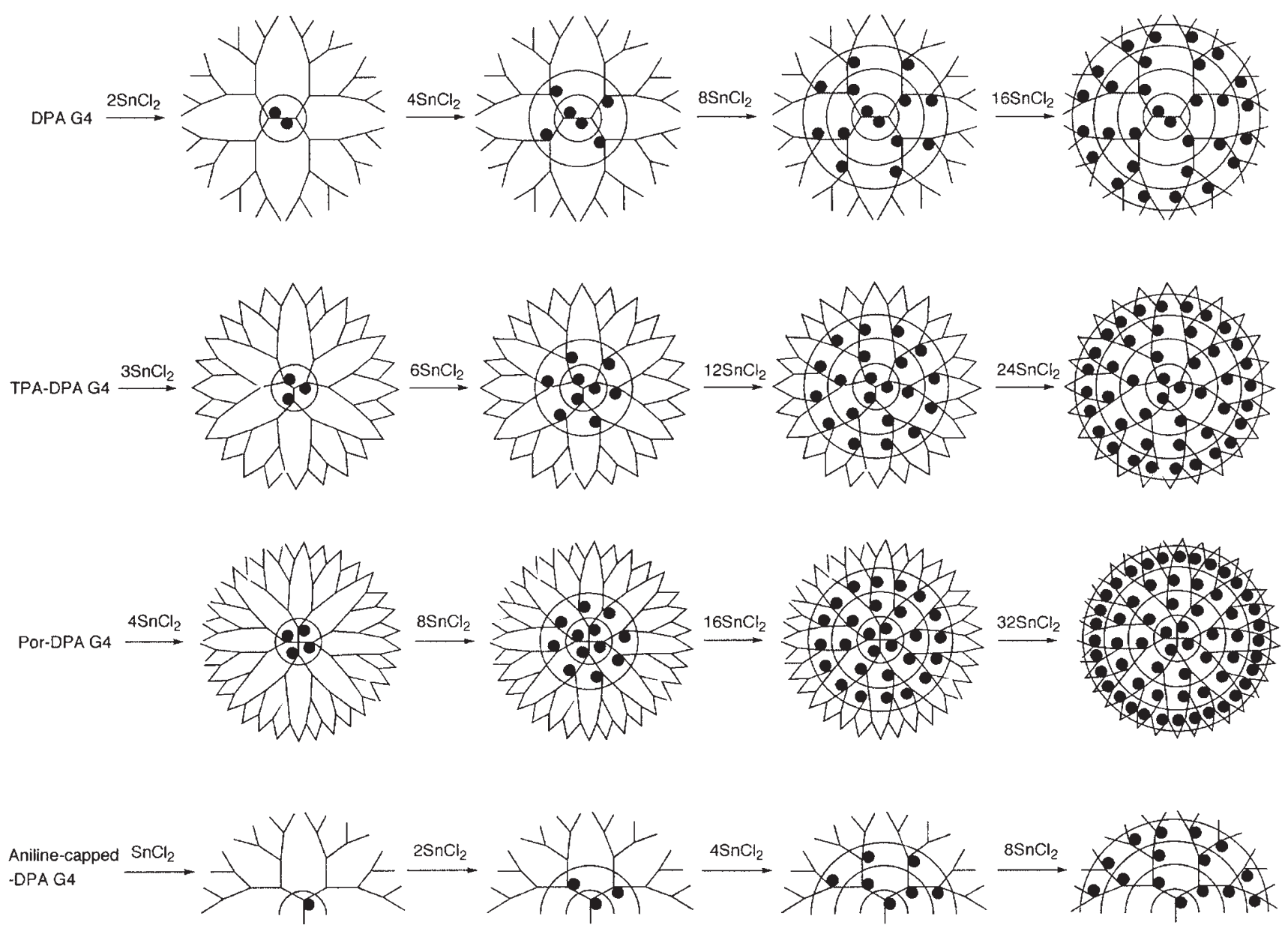

Scheme 2. Stepwise radial complexation in DPA derivatives.

served in the spectra. In TPA-DPA G4 (Scheme 2b), the shifts occur after the addition of 3, 6, 12, and 24 equivalents of $\mathrm{SnCl}_{2}$. In Por-DPA (Scheme 2c), the shifts occur after the addition of $4,8,16$, and 32 equivalents. In the aniline-capped DPA G4 (Scheme 2d), the shifts occur after the addition of 1,2, 4, and 8 equivalents. In each dendrimer, the amounts of $\mathrm{SnCl}_{2}$ added to the solution agree with the number of imines in the 1 st to 4 th shells. These results support that the complexation in DPA derivatives proceeds from the core imines to the terminal ones. The basicity of the inner imines is enhanced by the electron-releasing effect of the outer imines, and the stepwise complexation is caused by the different basicity of the imines between the shells. This complexation behavior means that the number and the position of the metal ions in the dendrimers are controllable.

\section{Coordination Constants}

The stepwise complexation behavior in DPAs suggests that the basicity of the inner imines is higher than that of the more peripheral imines. The different basicity of the imines between the shells in DPAs is supported by the comparison of their coordination constants. We determined the coordination constant of four kinds of imines in the aniline-capped DPA G4 with trifluoroacetic acid based on the calculation of the concentration profiles using the multi-equilibrium. The shifts of the isosbestic points and the absorbance of the absorption attributed to the complexed imines during the titration were simulated, and the result supported the idea that $\mathrm{SnCl}_{2}$ molecules are incorporated inside the dendron in the order of 1 st (one imine), 2nd (two imines), 3rd (four imines), and 4th (eight imines) shells. The coordination constants of the imines in the 1st to 4th shell of the aniline-capped DPA G4 were estimated to be $K_{1}=1.5 \times 10^{7} \mathrm{~mol}^{-1}$ $\mathrm{L}, K_{2}=3.0 \times 10^{5} \mathrm{~mol}^{-1} \mathrm{~L}, K_{3}=1.4 \times 10^{4} \mathrm{~mol}^{-1} \mathrm{~L}$, and $K_{4}=1.2 \times 10^{3} \mathrm{~mol}^{-1} \mathrm{~L}$, respectively (Figure 2). This result clearly shows that the basicity of the inner imines is enhanced by the electron-releasing effect of the outer imines and the differences of the coordination constants among the neighboring shells are over ten times. Similarly, the coordination constants in the 1st to 3rd shells of the aniline-capped DPA G3 were $K_{1}=1.3 \times 10^{7} \mathrm{~mol}^{-1} \mathrm{~L}, K_{2}=2.0 \times 10^{5} \mathrm{~mol}^{-1}$ $\mathrm{L}$, and $K_{3}=1.0 \times 10^{3} \mathrm{~mol}^{-1} \mathrm{~L}$, respectively, and the constants in the 1st and 2nd shells of the aniline-capped DPA G2 were $K_{1}=7.0 \times 10^{4} \mathrm{~mol}^{-1} \mathrm{~L}$, and $K_{2}=$ $9.0 \times 10^{2} \mathrm{~mol}^{-1} \mathrm{~L}$, respectively. 


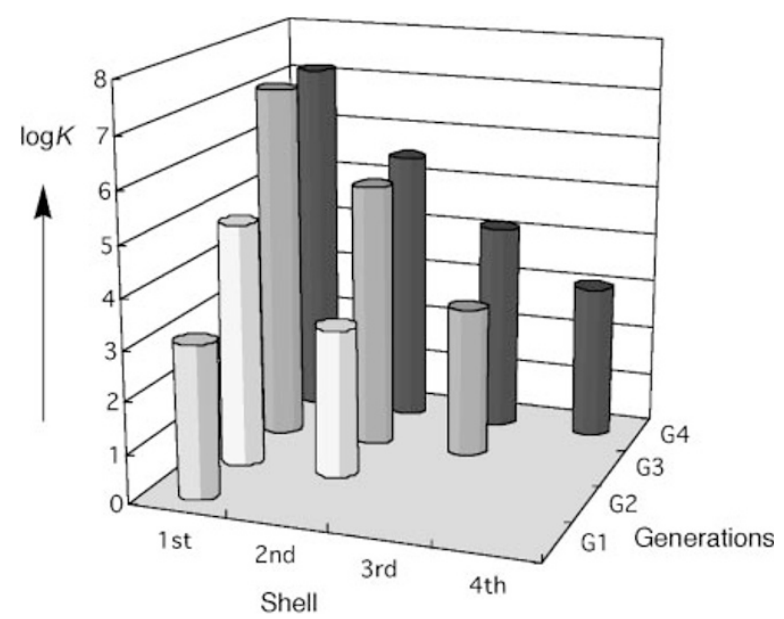

Figure 2. Complexation constants of trifluoroacetic acid with each shell's imines in aniline-capped DPAs.

\section{Control of the Number and Location of Metal Ions in DPAs}

The order of complexation among the shells in the DPAs permits control by the introduction of electrowithdrawing or -releasing groups to the core or terminals of the DPA, because the complexation order obeys the gradients of basicity of the imines among the shells. DPAs derivatives having fluorine as an electron-withdrawing group at the core (DPA-F G13) were synthesized via dehydration of tetrafluoro1,4-phenylenediamine with DPA dendrons. Introduction of fluorine to the core in DPAs strongly reduced the basicity of the core imines. The coordination constant of an imine in DPA-F G1 $(\log K=2.9$, in $1: 1$ dichloromethane:acetonitrile solution) was much smaller than that of DPA G1 $(\log K=5.0)$. During the complexation of DPA-F G2 with $\mathrm{SnCl}_{2}$, two shifts in the isosbestic point appeared on adding $0-4$ and
5-6 equivalents of $\mathrm{SnCl}_{2}$ in the UV-vis spectra. This result shows that the imines present in the 2nd shell were complexed first and then those present in the 1 st shell, whose basicity was lowered by the electron-withdrawing group. On adding $\mathrm{SnCl}_{2}$ to DPA-F G3, three shifts of the isosbestic point appeared upon adding 0-4, 5-12, and 13-14 equivalents of $\mathrm{SnCl}_{2}$. That is, the imines present in the 2nd shell were complexed first, then those present in the 3rd shell, and finally those present in the 1 st shell (Scheme 3).

\section{MODIFICATION AT THE CORE AND TERMINALS OF DPA}

An imine is reduced to a secondary amine by a reductant such as $\mathrm{NaBH}_{4}$. This reduction is accelerated in the presence of protic acids or Lewis acids. Based on the different rate of reduction, the complex of DPA G2 with two equivalents of $\mathrm{SnCl}_{2}$ was selectively reduced to DPA G2 having two amines at the 1st shell in the presence of $\mathrm{NaBH}_{4}$. Similarly, the reduction of DPA G4 complexed with two equivalents of $\mathrm{SnCl}_{2}$ in the presence of $\mathrm{NaBH}_{4}$ gave DPA G2 having two amines at the core. The "shell-selective reduction" supports the stepwise radial complexation that the two equivalents of $\mathrm{SnCl}_{2}$ are coordinated to the two imines at the 1st shell of DPAs. In addition, the amine units of the DPAs formed using the shell-selective reduction method can be functionalized by various carboxylic acids. For example, DPA derivatives having a ferrocene unit at the core were synthesized by the dehydration of DPA having two amines at the core with ferroceneacetic acid (Figure 3a).

In general, dendrimers synthesized via the convergent method have inactive terminals. Therefore, it is difficult to modify the terminals of the obtained den-
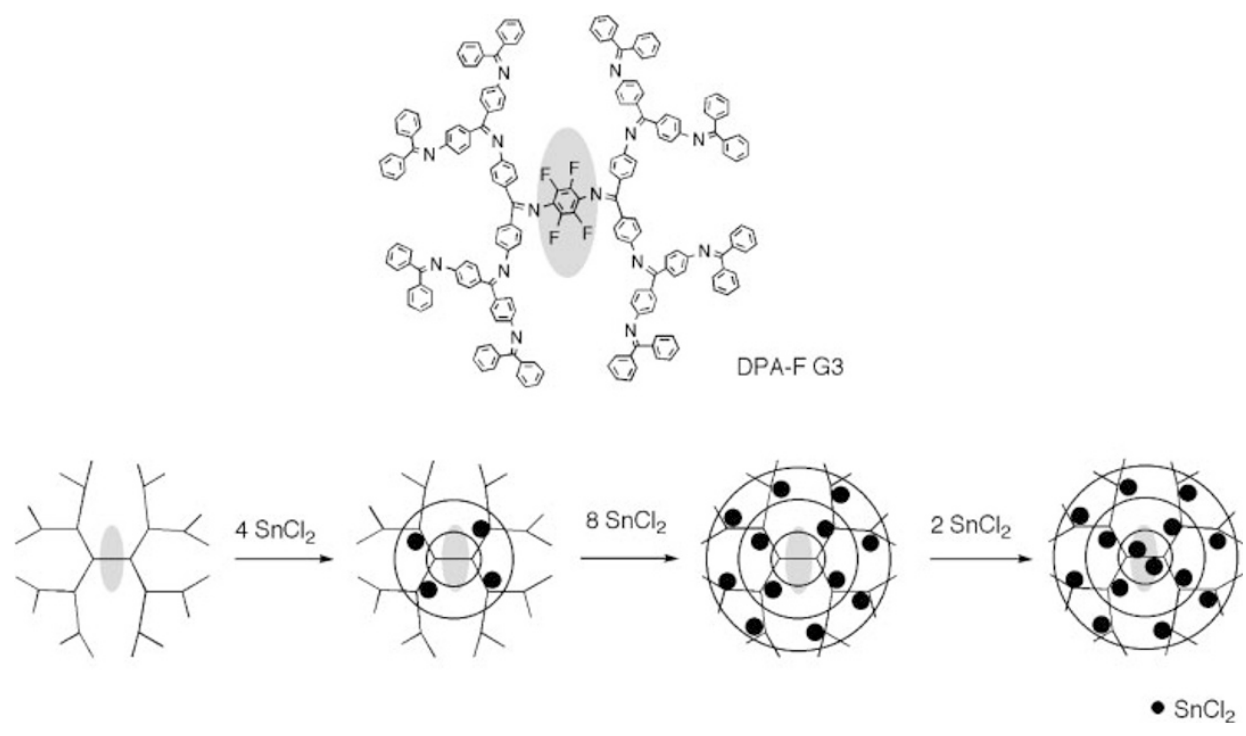

Scheme 3. Stepwise complexation behavior in DPA-F G3. 

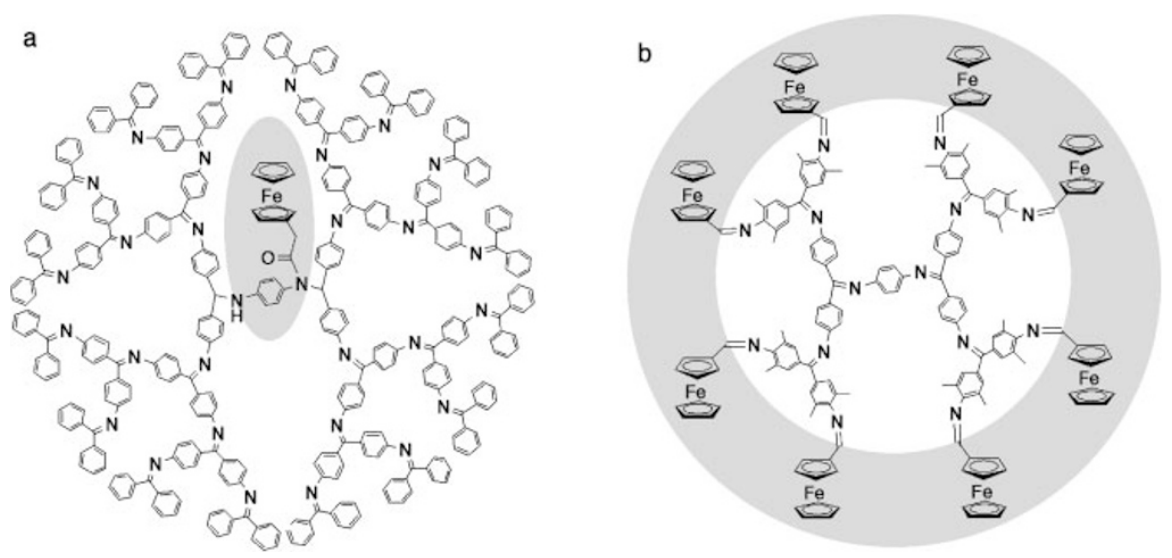

Figure 3. DPA derivatives having ferrocene unit(s) at the (a) core and (b) terminals.

drimers. We found that the amino groups of the tetramethyl-substituted diaminobenzophenone do not react with the carbonyl group of benzophenone at all under the synthetic conditions in the imine formation reaction. Based on this substrate specificity in this reaction, the dehydration of tetramethyl-substituted diaminobenzophenone with diaminobenzophenone selectively gave the DPA dendrons G2 and G3 having four and eight amino groups at the terminals, respectively. DPA G3 derivatives having eight amino groups at the terminals obtained via this synthetic method was easily ferrocene-modified at the terminals (Figure $3 b$ ).

\section{SWITCHING OF ENCAPSULATION/RELEASING OF IRON IONS IN DPA}

Iron shows interesting properties such as magnetism, ${ }^{41,42}$ redox chemistry, ${ }^{43,44}$ and catalysis ${ }^{45,46}$ and is also one of the essential elements of our body. Iron storage proteins called ferritins exists in the liver. ${ }^{47}$ The encapsulation and release of iron ions in the ferritin is controlled by the oxidation states of iron in the protein shell. We succeeded in controlling the "encapsulation/release" of iron ions in the DPAs through the redox switching driven by the $\mathrm{Fe}^{2+} / \mathrm{Fe}^{3+}$ couple. This ferritin-like switching behavior of iron ions in DPAs should prove to be useful for creating a drug delivery system.

The imines in the DPAs act as strong coordination sites with the $\mathrm{Fe}$ (III) ions. The complexation of $\mathrm{FeCl}_{3}$ with $\mathrm{Ph}_{2} \mathrm{C}=\mathrm{NPh}$ (DPA G0) was observed by means of UV-vis spectroscopy. During the titration with $\mathrm{FeCl}_{3}$, the solution of DPA G0 that has one imine group changes from transparent to yellow. A Job plot in chloroform/acetonitrile (1/1) solvent shows a maximum at a $0.5 \mathrm{~mol}$ fraction of DPA G0, i.e., DPA G0 is equimolar with $\mathrm{FeCl}_{3}$. This result supports the idea that the imine forms a $1: 1 \mathrm{imine} / \mathrm{FeCl}_{3}$ complex. The coordination constant, $K$, was determined to be $c a$.
$10^{8} \mathrm{M}^{-1}$, which is 100 times greater than that of $\mathrm{SnCl}_{2}$, by curve-fitting a theoretical simulation to the experimental data.

DPA G4 having 30 imine groups should assemble $30 \mathrm{FeCl}_{3}$ molecules, because the imine group quantitatively complexes $\mathrm{FeCl}_{3}$. During the addition of $\mathrm{FeCl}_{3}$, the color of the chloroform/acetonitrile solution of DPA G4 changed from yellow to orange due to the complexation. Using UV-vis spectroscopy to monitor the titration until 30 equivalents of $\mathrm{FeCl}_{3}$ had been added, the absorption at $410 \mathrm{~nm}$ increased without the isosbestic points. However, when subtracting the absorbance of $\mathrm{FeCl}_{3}$ possessing absorptions at 310 and $360 \mathrm{~nm}$ from the spectra, we observed a decrease at the $\pi-\pi^{*}$ absorption of the imine bonds at $335 \mathrm{~nm}$ and four changes in the position of the isosbestic point, indicating that the complexation proceeds not randomly, but stepwise. These four shifts in the isosbestic points are similar to the complexation with $\mathrm{SnCl}_{2}$. The number of added equivalents of $\mathrm{FeCl}_{3}$ that induced the shifts in the isosbestic points is in good agreement with the number of imine sites for each generation of DPA G4. This means that the complexing process with $\mathrm{FeCl}_{3}$ proceeds in a stepwise fashion from the core imines to the terminal imines of DPA G4, similar to that with $\mathrm{SnCl}_{2}$.

The redox behavior in DPA G4 complexed with 30 equivalents of $\mathrm{FeCl}_{3}$ was observed by spectroelectrochemical measurements. When the applied potential was changed from $+0.5 \mathrm{~V}$ to $-0.5 \mathrm{~V} v s$. $\mathrm{Ag} / \mathrm{Ag}^{+}$to reduce of $\mathrm{Fe}$ (III) salt to $\mathrm{Fe}(\mathrm{II})$ one, the absorption band attributed to the complex around $410 \mathrm{~nm}$ decreased, and then the spectra agreed with that of the DPA G4 without metals. $\mathrm{FeCl}_{2}$ is not coordinated to DPA G0 due to the weak Lewis acidity $(K=c a$. $0.8 \mathrm{M}^{-1}$ ). These results indicate that Fe ions are released from DPA G4 because of the drastic decrease in the coordination constants attributed to the reduction of $\mathrm{Fe}(\mathrm{III})$ to $\mathrm{Fe}(\mathrm{II})$ (Scheme 4). It is reasonable 


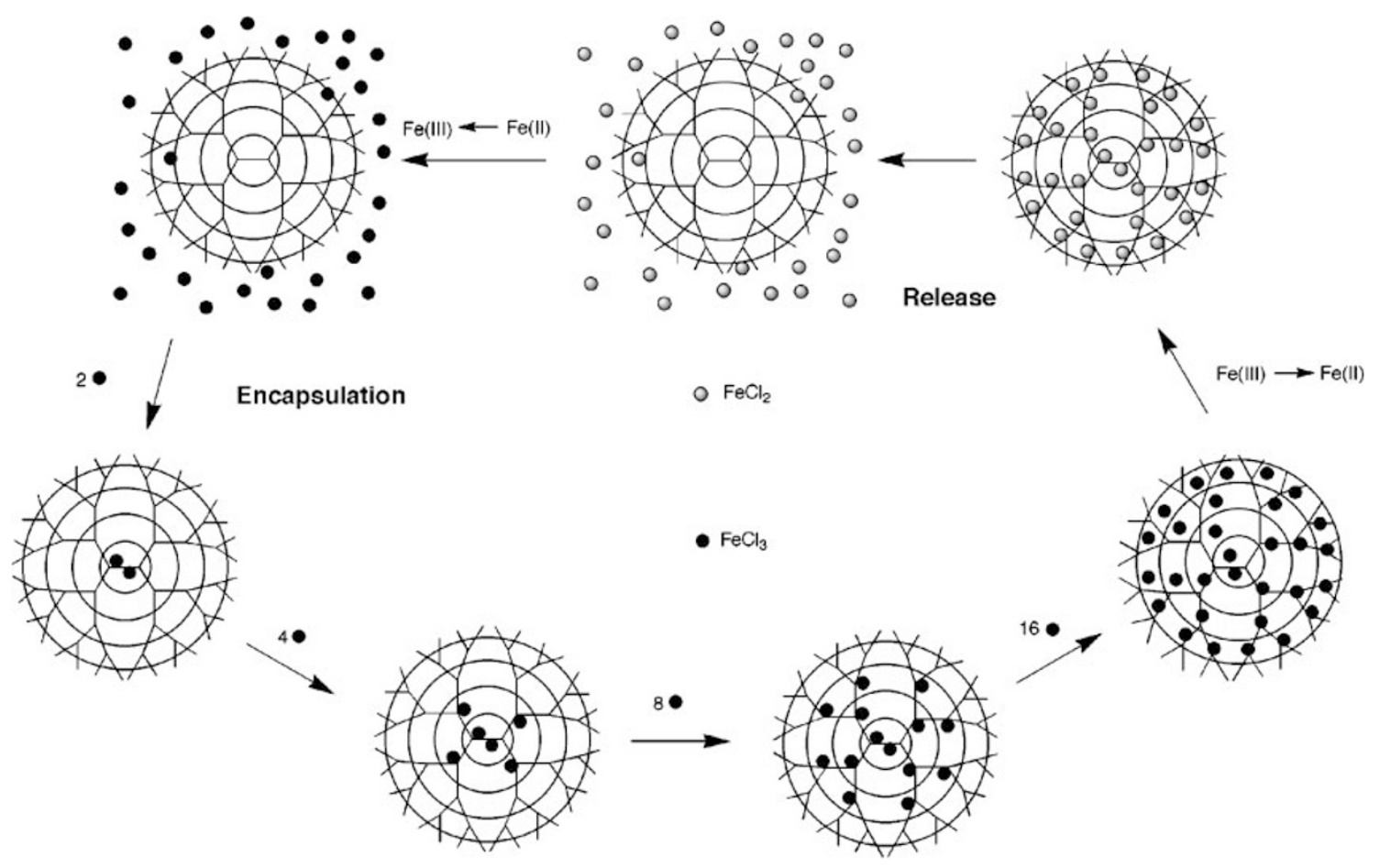

Scheme 4. Electrochemical control of encapsulation/releasing of iron ions in DPAs.

to find a reversible assembly of $\mathrm{Fe}$ ions through electrochemical oxidation, which allows the electrochemical switching of the encapsulation/release of Fe ions in the dendrimer like the iron storage protein, ferritin. The result shows one of the steps to create a novel intelligent drug delivery system using highly organized material.

\section{ELECTROLUMINESCENCE DEVICES USING DPA}

Triarylamines play an important role as a holetransport material in electronic devices such as organic light-emitting diodes (OLEDs) and photo cells. ${ }^{48}$ However, their monomeric molecules ${ }^{49-51}$ do not exhibit a high hole-transport efficiency because of their crystallinity, low mobile ability, or low thermal stability. Convenient solution processing has been also desired as the preparation of these devices with a large area. Dendritic macromolecules having a sphere-like and rigid structure makes it easy to prepare a homogeneous film by casting. To make the dendric molecule act as an efficient hole-transport compound, a novel charge-transport system needs to be constructed through the dendron shell between the hole-transport core. ${ }^{52}$ We synthesized TPA-DPA G1-4 as novel dendrimers with an arylamine as the core. TPA-DPAs are applicable as a hole-transport material in an EL device, using metal-assembling properties in which the metal acts as a mediator of the hole transfer.

The triarylamine unit at the core of the TPA-DPAs shows a redox wave of the $\mathrm{N} / \mathrm{N}^{+} \bullet$ couple at $0.5 \mathrm{~V} v s$.
$\mathrm{Ag} / \mathrm{Ag}^{+}$in the cyclic voltammogram. Based on the shell-effect in TPA-DPAs, the redox wave became broadened with an increase in the generation. The broad waves are caused not by the decrease in the diffusion coefficient but by the electrontransfer rate, because the diffusion coefficients calculated using the hydrodynamic radius have the same order of G1 and G4 that were determined to be $4.92 \times 10^{6}$ and $2.24 \times$ $10^{6} \mathrm{~cm}^{2} \mathrm{~s}^{-1}$, respectively. An increase in the distance between the electrode and the core with an increase of the generation results in a decrease in the electrontransfer rate. This suggests that the shell-effect of the dendrimer is occurring. On the other hand, TPADPA G4 associated with one equivalent of $\mathrm{SnCl}_{2}$ on the electrode shows a reversible redox wave at $0.5 \mathrm{~V}$, which suggests that $\mathrm{SnCl}_{2}$ promotes the mediation of the electron transfer in the dendrimer.

Organic light-emitting diodes (OLEDs) were fabricated, which used the TPA-DPA G1-4 and the TPADPA G1-4 complexed with $\mathrm{SnCl}_{2}$ as the hole-transport materials and tris(8-hydroxyquinoline)aluminum (Alq) as the luminance layer (Figure 4). The precisely controlled TPA-DPAs with one $\mathrm{SnCl}_{2}$ versus the imine bonds act as an excellent hole-transport material, even though TPA-DPAs without metal ions do not show EL activity. The EL performances of the devices using the TPA-DPA-metal complexes are drastically increased ( $c a .20$ times) by metal complexation. The current versus the applied bias voltage is lower, and the efficiency becomes higher by the complexation. Only one $\mathrm{SnCl}_{2}$ plays an important role as a hole-carrier through the dendron shell and enhances the hole- 


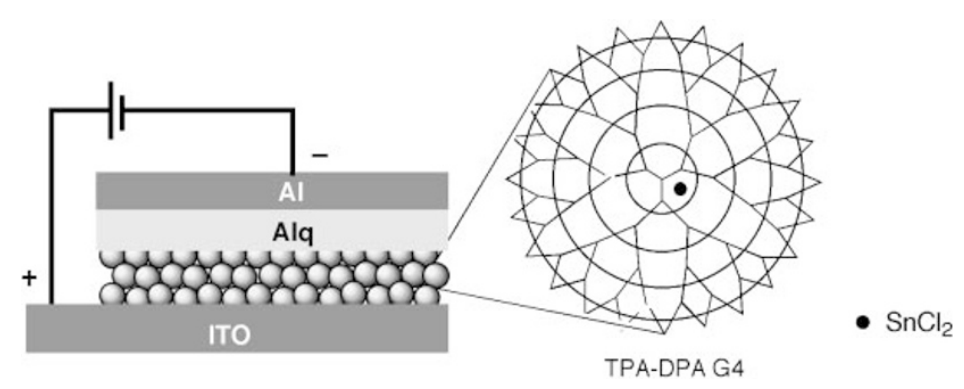

Figure 4. Electro-luminescence (EL) device using TPA-DPAs as a hole-transporting materials.

transport ability of TPA-DPA. The increasing efficiency of OLED in the generation is based on the processibility of the dendrimer. As compared to the generation, TPA-DPA G3 shows the best luminance intensity in its dendrimers.

\section{CONCLUDING REMARKS}

Precise control of the number and position of metal ions in the polymer materials is essential for the development of organic-metallic hybrid nano-materials. We exploited dendritic polyphenylazomethines (DPAs) as novel $\pi$-cojugated polymer ligands with a single molecular weight and a clearly-defined structure, and we first realized the precise metal-assembling in DPAs based on the unique stepwise complexation behavior. DPAs were synthesized by the convergent method via dehydration of aromatic ketones with aromatic amines in the presence of $\mathrm{TiCl}_{4}$. Using the DPA dendrons, various DPA derivatives having tris(thienylphenyl)amine and tetraphenylporphyrin as the core, or aniline-capped DPAs were also synthesized. The fifth generation DPA (DPA G5) was obtained via more efficient synthetic method than the conventional one. The stepwise complexation was observed in DPAs as stepwise shifts of the isosbestic point in the UV-vis spectra. DPA G4 has $2,4,8$, and 16 imine groups in the 1st, 2nd, 3rd and 4th shells, respectively (total, 30 imine groups). DPA G4 can trap 30 equivalents of $\mathrm{SnCl}_{2}$ molecules, because the imine group is complexed with $\mathrm{SnCl}_{2}$ at a ratio of 1:1. During addition of 30 equivalents of $\mathrm{SnCl}_{2}$ to DPA G4, four shifts in the isosbestic point were observed in the UV-vis spectra; the amount of $\mathrm{SnCl}_{2}$ added in each step is in agreement with the number of the imine groups in each shell of DPA G4. This result shows that the complexation of the imine groups in DPA G4 with $\mathrm{SnCl}_{2}$ occurs stepwise in the order of the 1st, 2nd, 3rd, and 4th shells. The stepwise complexation is caused by the different basicity of the imine groups between the shells. The gradients in the basicity were controlled by the introduction of electron-withdrawing groups to the core of the dendri- mers; the core imines were complexed last in DPAs having a 2,3,5,6-tetrafluoro-core due to the low basicity of the core imines. The stepwise complexation was supported by a novel shell-selective reduction (SSR) method for imines. The shell-selective reduction of imines is useful not only to support the unique complexation behavior, but to modify the core of DPAs with a ferrocene unit. Using the improved synthetic method of DPAs, the terminals of DPAs were functionalized by ferrocene units. Electrochemical switching during encapsulation/releasing of Fe ions in DPA was successful based on the significant difference in the coordination constants between the $\mathrm{Fe}(\mathrm{II})$ and $\mathrm{Fe}$ (III) ions with the imines. DPAs also work as hole-transporting materials in EL devices, and their efficiency was enhanced by the addition of $\mathrm{SnCl}_{2}$.

Acknowledgment. This work was partially supported by CREST from Japan Science and Technology Agency, Grants-in-Aid for Scientific Research (Nos. 15036262, 15655019, 15350073), and the 21st COE Program (Keio-LCC) from the Ministry of Education, Culture, Sports, Science and Technology Foundation, and a Research Grant (Project No. 23) from Kanagawa Academy Science and Technology (KAST).

\section{REFERENCES}

1. Z. F. Liu, H. C. Yan, K. B. Wang, T. Y. Kuang, J. P. Zhang, L. L. Gui, X. M. An, and W. R. Chang, Nature, 428, 287 (2004).

2. A. Ben-Shem, F. Frolow, and N. Nelson, Nature, 426, 630 (2003).

3. A. Zouni, H. T. Witt, J. Kern, P. Fromme, N. Krauss, W. Saenger, and P. Orth, Nature, 409, 739 (2001).

4. P. Jordan, P. Fromme, H. T. Witt, O. Klukas, W. Saenger, and N. Krauss, Nature, 411, 909 (2001).

5. P. A. delGiorgio, J. J. Cole, and A. Cimbleris, Nature, 385, 148 (1997).

6. G. T. Babcock and M. Wikstrom, Nature, 356, 301 (1992).

7. F. Ciardelli, E. Tsuchida, and D. Worle, Ed., "Macromolecular-metal Complexes," Springer-Verlag, Berlin, 1995.

8. C. U. Pittman, B. M. Cullberston, J. E., Sheet, Ed., "Metal 
Containing Polymeric Materials," ACS Symposium Series, Plenum Press, New York, N.Y., 1996.

9. E. Tsuchida, Ed., "Macromolecular Complexes," VCH Publisher, New York, N.Y., 1991.

10. D. A. Tomalia, J. Dewald, M. Hall, S. Martin, and P. B. Smith, Prepr. SPSJ Int. Polym. Conf., 1st, 65 (1984).

11. D. A. Tomalia, H. Baker, and J. R. Dewald, Polym. J., 17, 117 (1985).

12. G. R. Newkome, Z. Q. Yao, G. R. Baker, and V. K. Gupta, J. Org. Chem., 50, 2003 (1985).

13. A. Ciferri, Ed., "Supramolecular Polymers," M. Dekker, New York, N.Y., 2000.

14. F. Vögtle, Ed., "Dendrimer I, II, III”, Springer, New York, N.Y., 2001.

15. G. R. Newkome, C. N. Moorefield, and F. Vögtle, Ed., "Dendrimer and Dendrons," Wiley-VCH, New York, N.Y., 2001.

16. D. A. Tomalia, A. M. Naylor, and W. A. Goddard III, Angew. Chem., Int. Ed. Engl., 29, 138 (1990).

17. M. Fischer and F. Vögtle, Angew. Chem., Int. Ed. Engl., 38, 884 (1999).

18. A. W. Bosman, H. M. Janssen, and E. W. Meijer, Chem. Rev., 99, 1665 (1999).

19. S. M. Grayson and J. M. J. Fréchet, Chem. Rev., 101, 3819 (2001).

20. C. Devadoss, P. Bharathi, and J. S. Moore, J. Am. Chem. Soc., 118, 9635 (1996).

21. D. L. Jiang and T. Aida, Nature, 388, 454 (1997).

22. T. D. Selby and S. C. Blackstock, J. Am. Chem. Soc., 120, 12155 (1998).

23. K. Aoi, K. Tsutsumiuchi, A. Yamamoto, and M. Okada, Tetrahedron, 53, 15415 (1997).

24. L. Crespo, G. Sanclimens, B. Montaner, R. Perez-Tomas, M. Royo, M. Pons, F. Albericio, and E. Giralt, J. Am. Chem. Soc., 124, 8876 (2002).

25. S. E. Stiriba, H. Frey, and R. Haag, Angew. Chem., Int. Ed. Engl., 41, 1329 (2002).

26. E. C. Wiener, F. P. Auteri, J. W. Chen, M. W. Brechbiel, O. A. Gansow, D. S. Schneider, R. L. Belford, R. B. Clarkson, and P. C. Lauterbur, J. Am. Chem. Soc., 118, 7774 (1996).

27. R. M. Crooks, M. Zhao, L. Sun, V. Chechik, and L. K. Yeung, Acc. Chem. Res., 34, 181 (2001).

28. G. R. Newkome, E. He, and C. N. Moorefield, Chem. Rev., 99, 1689 (1999).

29. D. Astruc and F. Chardac, Chem. Rev., 101, 2991 (2001).

30. V. Balzani, P. Ceroni, A. Juris, M. Venturi, S. Campagna,
F. Puntoriero, and S. Serroni, Coord. Chem. Rev., 219, 545 (2001).

31. M. Higuchi, S. Shiki, and K. Yamamoto, Org. Lett., 2, 3079 (2000).

32. M. Higuchi, S. Shiki, K. Ariga, and K. Yamamoto, J. Am. Chem. Soc., 123, 4414 (2001).

33. M. Higuchi and K. Yamamoto, J. Syn. Org. Chem. Jpn., 60, 869 (2002).

34. N. Sato, J.-S. Cho, M. Higuchi, and K. Yamamoto, J. Am. Chem. Soc., 125, 8104 (2003).

35. T. Imaoka, H. Horiguchi, and K. Yamamoto, J. Am. Chem. Soc., 125, 340 (2003).

36. K. Takanashi, H. Chiba, M. Higuchi, and K. Yamamoto, Org. Lett., 6, 1709 (2004).

37. K. Yamamoto, M. Higuchi, S. Shiki, M. Tsuruta, and H. Chiba, Nature, 415, 509 (2002).

38. M. Higuchi, M. Tsuruta, H. Chiba, S. Shiki, and K. Yamamoto, J. Am. Chem. Soc., 125, 9988 (2003).

39. M. Higuchi and K. Yamamoto, Bull. Chem. Soc. Jpn. 77, 853 (2004).

40. K. Yamamoto and M. Higuchi, J. Syn. Org. Chem. Jpn., 62 433 (2004).

41. S. Sun and H. Zeng, J. Am. Chem. Soc., 124, 8204 (2002).

42. M. Rajamathi, M. Ghosh, and R. Seshadri, Chem. Commun., 2002, 1152.

43. M. C. Daniel, J. Ruiz, and D. Astruc, J. Am. Chem. Soc., 125, 1150 (2003).

44. L. J. C. Jeuken, A. K. Jones, S. K. Chapman, G. Cecchini, and F. A. Armstrong, J. Am. Chem. Soc., 124, 5702 (2002).

45. H. C. Choi, W. Kim, D. Wang, and H. Dai, J. Phys. Chem. $B, \mathbf{1 0 6}, 12361$ (2002).

46. M. F. Mayer and M. M. Hossain, J. Org. Chem., 63, 6839 (1998).

47. M. A. Zapien and M. A. Johnson, J. Electroanal. Chem., 494, 114 (2000).

48. C. W. Tang and S. A. VanSlyke, Appl. Phys. Lett., 52, 913 (1987).

49. J. H. Burroughes, D. D. C. Bradley, A. R. Brown, R. N. Marks, K. Mackay, R. H. Friend, P. L. Burn, and A. B. Holmes, Nature, 347, 539 (1990).

50. R. H. Friend, R. W. Gymer, A. B. Holmes, J. H. Burroughes, R. N. Marks, C. Taliani, D. C. C. Bradley, D. A. Dos Santos, J. L. Bredas, M. Logdlund, and W. R. Salaneck, Nature, 397, 121 (1999).

51. T. Noda and Y. Shirota, J. Lumin., 87-89, 1168 (2000).

52. D. Ma, J. M. Lupton, D. W. Samuel, S. Lo, and P. L. Burn, Appl. Phys. Lett., 81, 2285 (2002).

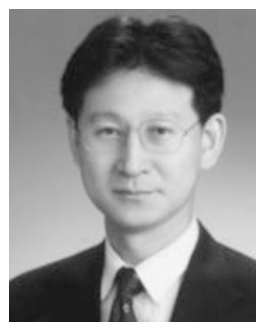

Kimihisa Yamamoto received BS, MS, and Ph. D. degrees from Waseda University in Polymer Chemistry in 1985, 1987, and 1990, respectively. Research Associate and Associate Professor of Waseda University from 1989 to 1990 and from 1991 to 1996, respectively. Associate Professor of Waseda University from 1993 to 1996. He is now a professor of department of chemistry in Keio university from 1997. Award for the Young Chemist from Chemical Society of Japan on 1996. Researcher of Japan Research Development Corporation for PRESTO project from 1992 to 1995. Project leader in Kanagawa Academy of Science and Technologies (KAST) from 2002 to 2004 and for the CREST project in Japan Science and Technology Agency (JST) from 2003 to present. He is engaged in developing supra-metallomolecules. He is a member of the Japan Chemical Society. 


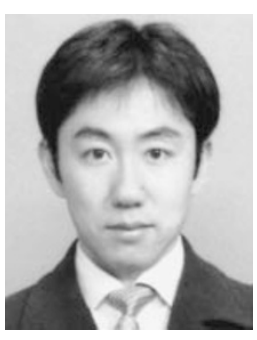

Masayoshi Higuchi was born in Niigata in 1969. He received Bachelor, Master, and Ph. D. degrees from Osaka University in 1993, 1995, and 1998, respectively. He started an academic career in Faculty of Science and Technology, Keio University as a Research Associate in 1998, and was promoted to an Assistant Professor in 2003. He also worked as a Research Fellow of the Japan Society for the Promotion of Science for Young Scientists (JSPS Research Fellow) in 1995-1998, and an investigator in Kanagawa Academy of Science and Technology (KAST) in 2001-2004, and a CREST investigator in Japan Science and Technology Agency (JST) in 2003-present. His current research has focused on organic-metallic hybrid nano-materials using novel topological $\pi$-conjugated supramolecules. He was rewarded the Chemical Society of Japan Award for Young Chemists in 2003. 